\title{
La teoría mimética de René Girard. Una visión crítica
}

The René Girard's mimetic theory. A critical approach

\section{Agustín Moreno Fernández}

Doctor en Filosofía. Miembro del grupo de investigación Antropología y Filosofía (PAIDI-SEJ 126) y del proyecto Las pasiones y la naturaleza humana (FFI2010-16650). Universidad de Granada.

morenofdez@ugr.es

\section{RESUMEN}

Estas páginas ofrecen un bosquejo de las líneas maestras de algunas críticas e interrogantes importantes que es necesario plantear a la teoría mimética de René Girard. Distinguimos dos niveles. Uno formal, referido a la interpretación que Girard hace de autores y textos. Otro más centrado en contenidos y conceptualizaciones, en referencia a sus dos elementos fundamentales, el deseo mimético y el chivo expiatorio.

\section{ABSTRACT}

This study offers a sketch of the main lines of some major critiques and questions that need to be formulated with respect to mimetic theory. We will distinguish two levels. On the one hand, the formal level, referring to the interpretation that Girard offers of authors and texts. On the other hand, it is the level more specifically referring to contents and conceptualizations, in reference to his two fundamental elements, the mimetic desire and the scapegoat.

PALABRAS CLAVE

crítica de la teoría mimética | René Girard | deseo mimético | mecanismo del chivo expiatorio

KEYWO RDS

critique of mimetic theory | René Girard | mimetic desire | scapegoat mechanism

\section{Introducción}

La teoría mimética de Girard, así como sus hipótesis sobre el deseo mimético y el mecanismo del chivo expiatorio, han tenido una gran repercusión, la cual ha ido incrementándose con el paso de los años. No obstante, no pocas veces se ha recibido o se cita su obra de manera acrítica o parcialmente selectiva, lo que hace preciso, en aras del rigor intelectual, ofrecer una comprensión de su pensamiento que no evacue los elementos no bien expuestos o desarrollados por Girard, o que resultan confusos y problemáticos.

Emprender una evaluación general de la teoría mimética de Girard podría ser empresa para un libro. El carácter interdisciplinar de su obra, las numerosas y diversas temáticas, corrientes y figuras del pensamiento que en ella están concernidos, o el gran alcance y repercusión de sus postulados en muy variados ámbitos serían elementos a tener en cuenta. En estas páginas nos limitaremos a ofrecer un bosquejo de por dónde irían las líneas maestras de algunas relevantes críticas e interrogantes que cabe plantear a la teoría mimética. Diferenciaremos de modo heurístico dos niveles. Un nivel formal, referido a la interpretación que Girard hace de autores y textos. Aquí nos detendremos en Platón, en la cuestión de los mitos y en la concepción girardiana del judeocristianismo. Y otro nivel más centrado en contenidos y conceptualizaciones, fundamentalmente en referencia a sus dos elementos principales: el deseo mimético y el mecanismo del chivo expiatorio (1).

\section{Nivel formal}

Con respecto a este nivel, cabría entrar en un debate con antropólogos, mitólogos, filólogos, exégetas, filósofos, historiadores, críticos literarios... ¿Son atinadas las interpretaciones que Girard ofrece de mitos, ritos, textos literarios, bíblicos, filosóficos...? ¿Están bien fundamentadas? ¿Están demasiado sesgadas conforme a sus pretensiones? No pretendemos, ni mucho menos, resolver estas cuestiones. Pero sí, como 
mínimo, y aunque esto no quiera decir que Girard yerre de plano en sus interpretaciones (ni en las que señalaremos, ni en todas), mostrar puntos de vista disconformes. Por ejemplo, en su interpretación de Platón, a la hora de seleccionar los mitos que analiza, o en su lectura del cristianismo.

A juicio de Stéphane Vinolo, Girard realiza un juicio abusivo cuando afirma que Platón no ve las consecuencias sociales de la mímesis. No obstante lo cual, el primero reconoce que, aunque la violencia social del doble sea incontestable, el gesto de apropiación permanece como el gran impensado o inconcebido de la teoría platónica de la mímesis (Vinolo 2005: 72). Es más, cabría abrir, más allá de Platón, el abanico de autores que posiblemente habrían afrontado el problema de la violencia mimética: Hobbes, Rousseau, Spinoza, Kierkegaard... (Boyer 1985: 570-571). Veamos en qué consiste la lectura girardiana de Platón según Vinolo. La imitación en Platón estaría siempre expresada en términos de imagen, representación, doble, copia. Pero en su obra estaría silenciado el hecho esencial de la teoría del deseo mimético, las derivas violentas de la mímesis. Girard reconoce que la problemática del deseo mimético estaría reconocida en el plano representativo del ser. No obstante, lamenta que Platón no haya dado cuenta del lado adquisitivo de la rivalidad mimética (mímesis de apropiación, ámbito del tener). Sin embargo, afirma Vinolo, este juicio de Girard sobre Platón, y esto sería también válido para el juicio que hace sobre la filosofía en general, resultaría abusivo y parcial. Opina que, aunque Platón no actualiza las consecuencias violentas de la mímesis de adquisición, "expresa de forma totalmente clara el hecho de que esta es una fuerza social muy virulenta de la cual hay que desconfiar y protegerse, no sólo por razones epistemológicas, sino también por razones prácticas y políticas" (Vinolo 2005: 59-61). Vinolo apela a los textos platónicos, defendiendo que Platón se interesa por los aspectos comportamentales de la mímesis aunque no los teorice como Girard. En La República, la mímesis se revelaría como violencia al hilo de la amenaza de la desagregación: "la política expulsa fuera de la ciudad, pone en su margen a los imitadores a causa de los comportamientos que generan (...). La denuncia de la mímesis deviene en política una denuncia de la acción y no ya solamente un cuestionamiento de la representación". Para Vinolo la intuición platónica en cuanto a las influencias comportamentales de la mímesis no deja ninguna duda y cita los siguientes textos: La República, III, 395c-d y La República, X, aludiendo a las artes dramáticas (Vinolo 2005: 69-70).

Pasemos al segundo ejemplo, referido a la interpretación de los mitos, de una muestra de disconformidad en la selección que Girard hace. Si bien el autor pone el acento en los casos de figuras míticas que son hermanos enemigos (Eteocles y Polinices, Rómulo y Remo, Caín y Abel...), ilustrando la rivalidad mimética asociada a la mediación interna (las relaciones de reciprocidad y rivalidad mimética entre iguales, sin barreras de jerarquía), habría dejado de lado, sin embargo, "el tema de los hermanos inseparables que nunca serán enemigos, siendo Cástor y Póllux los ejemplos más resaltantes” (Andrade 2007: 80)(2).

Hay también quien reprocha a Girard un "completo desprecio" por los textos, como los de las novelas, ya que sus interpretaciones de estos estarían supeditadas a ajustarlos a su teoría. Así, afirma René Pommier que, muy lejos de que las obras de Racine y Molière puedan servir para sostener las tesis de René Girard, encontraríamos allí ejemplos para contradecirlas. El autor se sirve de ejemplos de estos autores, como el Don Juan, o aún de otros como de Don Quijote, utilizados por Girard, para darles la vuelta y mostrar, a su juicio, contradicciones o interpretaciones erróneas (Pommier 2010: 24)(3).

En cualquier caso, nos interesan, más allá de la más o menos ortodoxa hermenéutica literaria girardiana, las conclusiones de ésta, cristalizadas en su teoría mimética. Precisamente en el paso de su hermenéutica literaria a la formulación de sus hipótesis sobre el deseo mimético, también podría cuestionarse su modo de proceder:

"La crítica literaria de Girard corre el riesgo de convertirse en apresuradamente inductiva. A partir de la experiencia de unos escasos personajes que ni siquiera son reales, Girard pretende arribar a unas conclusiones demasiado generalizadas: en función de cinco novelistas aspira a construir toda una teoría sobre la personalidad humana y el deseo. Con suficiente perspicacia, Girard ha logrado una transición de la crítica literaria a la psicología social. Pero, sus 'casos' son muy reducidos, y ni siquiera observados directamente. Girard no tiene a ningún paciente que interrogar, ningún sueño que analizar" (Andrade 2007: 155-156).

Por último, también mencionaremos un ámbito de posible discusión de la hermenéutica girardiana, en este caso, en lo que se refiere a su exégesis de los textos judeocristianos. La cantidad de cuestiones objeto de debate podría ser casi interminable, dada la profusión de detalle con que Girard analiza numerosos pasajes, episodios y libros bíblicos. Aquí nos ceñiremos a un botón de muestra de una crítica general, la de L. Scubla, 
que establece una separación y un contraste entre las interpretaciones de Girard y las escrituras evangélicas. A su juicio no son las segundas, sino las primeras, las que tendrían como objeto la comprensión del mecanismo victimario. El mérito o el enriquecimiento de la comprensión de la teoría mimética no estaría tanto en los textos neotestamentarios como en la lectura girardiana de los mismos:

"Es posible que el Jesús histórico haya querido recusar la vieja noción de cólera divina, abolir el sacrificio y revelar el mecanismo victimario; pero, si es el caso, no es probablemente demostrable. Por el contrario, apenas es dudoso que no sabríamos atribuir tales propósitos al Cristo de los Evangelios; incluso si no lo hemos demostrado, creemos haber al menos establecido la posibilidad de una tal demostración. (...) Es falso afirmar que el mecanismo victimario es revelado por primera vez en la Escritura y que basta leer el texto judeocristiano para poder a continuación leer todos los otros textos. No es el Nuevo Testamento el que nos permite comprender lo religioso primitivo, es la antropología girardiana la que enriquece considerablemente nuestra comprensión del cristianismo. El cristianismo de René Girard no es por tanto el de los Evangelios. Pero, ¿es, por otra parte, del todo compatible con los principales resultados de la antropología religiosa de nuestro autor? La cuestión puede parecer paradójica, pero creemos que vale la pena plantearla" (Scubla 1985: 250).

Hay que matizar esta crítica, teniendo en cuenta que este texto está compuesto antes del cambio de Girard hacia una concepción del cristianismo no incompatible con la noción de sacrificio. Esta crítica sería, en cierto sentido, concomitante con la crítica de Pommier que citaremos más adelante, que ve en Girard una especie de autoconcebido mesías que "tenía" que venir a dar la auténtica interpretación del cristianismo.

Finalmente, bajo el epígrafe de "Nivel formal" no podemos dejar de cuestionar el modo de proceder de Girard en cuanto que, en no pocas ocasiones, echamos en falta en su obra un mayor esfuerzo de sistematización y de rigor, algo a lo que no ayuda una producción intelectual en la que demasiadas obras tienen el carácter de largas entrevistas, aunque otras ventajas se deriven de ello. Además, echamos de menos un mayor esfuerzo por citar de modo más preciso autores y obras, o por ahondar en ellos, máxime cuando tiene palabras de gran admiración o considera que su obra o su pensamiento se aproximan mucho a autores como san Agustín o Pascal.

\section{Nivel de contenidos}

\subsection{Deseo mimético}

Aunque la formulación del deseo mimético se pretende sencilla, y así lo es en bastantes de sus expresiones a lo largo de la obra girardiana, no es menos cierto que es necesario intentar esclarecer la concepción girardiana del deseo, poniendo de relieve algunas carencias, ambigüedades y contradicciones de Girard al respecto, además de bosquejar los presupuestos teóricos de la misma (Moreno Fernández 2013: 125-147). Una crítica más frecuente entre quienes discuten a Girard, pero que puede suscitarnos la teoría mimética a cualquiera, es la objeción de estar ante un planteamiento reduccionista que, cegado por una sola clave, en este caso la del mimetismo, pretendería explicarlo todo bajo su luz de forma simplificadora. Una de las temáticas que expresa y concreta este reduccionismo se plantea cuando abordamos el problema de la libertad y la autonomía del ser humano en la teoría mimética. Y es que, una lectura general de sus principales obras puede llevarnos a pensar, y de manera justificada, que el reduccionismo de Girard, a la hora de explicar el comportamiento y los deseos humanos, principalmente conforme al mimetismo como clave explicativa principal, y sus dinámicas de reciprocidad (violenta o no), conduce inexorablemente a la negación de la libertad y de la autonomía del sujeto. Máxime cuando este queda deconstruido a través de la psicología interdividual.

Sin embargo, una lectura más atenta y detallada del corpus girardiano nos abre el horizonte no sólo de una lectura "negacionista" de la libertad, sino de otra lectura opuesta, en rescate de una subjetividad humana capaz de autonomía y libertad. De manera que, al igual que podemos ver el reduccionismo de Girard al respecto del deseo mimético, que estaría por todas partes, también hay que atender a sus matizaciones, aunque, salvo contadas menciones, resultan escasas, insuficientes y superficiales (Moreno Fernández 2013: 295-302; 321-353). En este sentido habría que decir que, sin negar la influencia constante de modelos culturales y sociales, y de los individuos que nos rodean, a la hora de desear, también es posible que nuestro deseo de algo permanezca porque encontremos en el objeto de deseo (persona, cosa, ideal) 
elementos objetivos y convincentes que lo hagan deseable. Cosa que Girard parece no haber tenido en cuenta (Boyer 1985: 581).

De igual modo, si bien tampoco podemos desdeñar la ineluctable influencia de modelos a la hora de configurar nuestra personalidad y en la orientación de nuestras metas y objetivos vitales y conductas éticas, no es menos cierto que Girard obvia algo tan frecuente y cotidiano como es el deseo, el anhelo, o el afán de justicia, verdad, bondad, belleza, conocimiento, sabiduría... Si bien, como afirma Gomá Lanzón, cabe armonizar el ideal ilustrado de emancipación con la imitación, en tanto imitación de los prototipos que encarnaran éste, y, de este modo, los ideales nombrados también serían susceptibles de ser encarnados e imitados (Gomá 2005: 534-535), Girard aún tendría que dar cuenta de cómo es posible que esos deseos puedan ser inagotables más allá de situaciones y contextos miméticos concretos. Podría aparecer aquí la idea del deseo inherente de la trascendencia vertical, el deseo religioso de lo Absoluto, pero incluso aquí el pensador no ha profundizado en la cuestión, limitándose a exponer el modelo jesuano de imitación (la imitación no competitiva, no rivalitaria, no conflictiva y generosa) para encauzar aquel, quedando sin problematizar.

Hablando también de reduccionismo, a O. Maurel le parece que Girard se queda corto con el mimetismo del aprendizaje y el mimetismo de apropiación, dejando fuera el mimetismo de la violencia (Maurel 2004: 202), con respecto al cual sería iluminador el pensamiento de A. Miller. Este mimetismo de la violencia tendría especial repercusión en la infancia, y no sólo sería relevante en el plano de la ontogénesis, sino también en el de la filogénesis:

"René Girard no parece haber tenido en cuenta hasta el presente, el hecho de que el mimetismo tiene efectos mucho más potentes sobre el niño que sobre el adulto, porque, sobre el niño, son literalmente constitutivos. El niño imita a una edad en la que su sistema nervioso no está terminado, en la que su cerebro está en pleno crecimiento y las experiencias de mimetismo que sufre son determinantes para su vida entera precisamente porque son sus primeras experiencias, las que modelan sus comportamientos fundamentales y las que le servirán de algún modo de normas para juzgar las siguientes. (...) En el adulto que ha sufrido la violencia en su infancia, el hecho de ser agredido o haber caído en un movimiento colectivo violento tiene muchos más riesgos de desencadenar una reacción violenta, porque reacciona más en función de su infancia, siempre presente en él, que en función de la situación presente y de la adaptación de esta reacción a su situación" (Maurel 2004: 205).

Así, no necesariamente sería preciso que haya un contexto de rivalidad mimética para que la violencia se desencadene, como en el caso del individuo que ha interiorizado pautas de conducta violentas y las manifiesta y las descarga, p. ej. infligiendo un castigo físico a sus hijos.

¿Y en el plano filogenético? También aquí el mimetismo de la violencia, con especial repercusión en los niños, tendría un papel, poniendo de manifiesto una carencia de Girard. Si bien la institución de ritos y prohibiciones habrían tenido una repercusión innegable en la educación de aquellos -y en la progresiva "educación" de la humanidad- faltaría poner el foco en la obligación impuesta a los niños para su seguimiento a través de los, en ocasiones crueles, ritos de iniciación. Aunque no compartimos la elucubración acerca de una supuesta comunidad humana primigenia, como parece destilarse de la siguiente cita, nos parece sugerente la idea principal:

"Los padres debieron entonces recurrir a la violencia y, teóricamente, en una generación todo pudo bascular. La primera generación de niños educados con violencia integró en el comportamiento de la humanidad una violencia adquirida pero de algún modo constitutiva ya que está adquirida desde la primera infancia. Esta generación reprodujo sobre sus propios niños la violencia que había sufrido, no solamente esta vez por una necesidad exterior (para obligar a sus niños a someterse a los ritos de iniciación), sino por una necesidad interior, la compulsión de repetición. Y podemos decir que a partir de este momento la humanidad se ha encerrado en un doble círculo de violencia: el círculo de la violencia mimética descrito por Girard y el círculo de la violencia infligida a los niños que hizo de cada niño que venía a este mundo la víctima emisaria de la compulsión de sus padres y un futuro reproductor de esta compulsión. Del mismo modo que la humanidad es la superviviente de múltiples crisis miméticas que han hecho de la sociedad la que es, es decir, violenta, la mayoría de los niños del mundo son los supervivientes (supervivientes en el sentido literal del término (...) de mini-crisis miméticas: la repetición por sus padres de lo que ellos mismos han sufrido como niños. (...) Si Alice Miller tiene razón, es vano invitar a los hombres a renunciar a la violencia en sus comportamientos de adultos sin 
indicarles lo que la provoca en la infancia y cómo remediarla. Ahora bien, el mimetismo de la violencia denunciado por Girard no es más que una causa segunda de la violencia. Puesto que el paso del mimetismo de aprendizaje al mimetismo de apropiación, después al mimetismo de la violencia no es absolutamente fatal. Lo es sobre todo en el caso de aquellos (la mayoría de los hombres actualmente) que han sido sometidos al ejemplo de la violencia desde su primera infancia por parte de aquellos que constituían su base de seguridad" (Maurel 2004: 219-221)(4).

Hablando del mimetismo y de su carácter problemático vinculado a la violencia, otra crítica susceptible de hacerse a Girard tiene que ver con su consideración marcadamente pesimista de las relaciones de simetría y de mediación interna, típicas de las sociedades modernas. En este sentido, si bien puede ser iluminadora la secuencia: deseo mimético-simetría/ mediación interna-indiferenciación-violencia, o la sentencia girardiana, según la cual, allí donde falta la diferencia, amenaza la violencia; no es menos cierto que esta concepción no agota todos los tipos de violencia. En este sentido González Faus interpela a Girard reclamándole "prestar más atención a todo tipo de conflictos disimétricos y opresores por los que simplemente el pez grande se come al chico; sobre todo por tratarse de un tipo de conflictos que suelen quedar en la historia como (des)órdenes establecidos" (González Faus 1998: 261-262). En esta línea también se ha visto en Girard una inclinación al conservadurismo político, aunque el autor ve carencias tanto en la izquierda (que considera al ser humano desarraigado) como en la derecha (tentada a mantener injustas diferencias indeseables fundadas en el pasado), y a pesar de que el igualitarismo moderno tendría entre sus fuentes la inspiración cristiana. No obstante lo cual el pensador valora de un modo más positivo las mediaciones externas, quedando pendiente su profundización en una valoración positiva de la simetría de las relaciones modernas.

\subsection{Mecanismo del chivo expiatorio}

De nuevo aquí cabría plantear una crítica al planteamiento de Girard en tanto que reduccionista. Y es que todas sus referencias a la sacralidad arcaica, asociada al mecanismo del chivo expiatorio, parecen no dejar lugar, entre crímenes, sangre, víctimas, sacrificios, ritos y prohibiciones, a una experiencia religiosa o de lo sagrado en términos de experimentación de la bondad, la benignidad, la turbación ante la grandeza o el sentimiento oceánico, la belleza, el gozo... atribuidos a una deidad, a una naturaleza sacralizada, o a lo inefable. Girard parece agotar la experiencia del enigma y el misterio religiosos a todo lo que rodea a los chivos expiatorios. Y, sin embargo, salta a la vista que la compleja fenomenología de lo religioso quedaría mutilada sin hacer referencia a otras muchas valoraciones en sentido "positivo", más allá de los enmascaramientos de las persecuciones y crímenes colectivos y sus efectos catárticos en los miembros de una comunidad. Como señala M. Fraijó no puede esquivarse la complejidad del fenómeno religioso y ha de tenerse en cuenta la diversidad de su vivencia por millones de seres humanos, que le asignan una variada gama de funciones y de sentidos para su existencia:

"La filosofía de la religión no puede prescindir de la fenomenología del hecho religioso. Lo más primordial será comprender el fenómeno religioso en la variedad de sus manifestaciones (...) en la historia de las religiones y de la cultura humana. (...) Todo lo grandioso, lo nuevo, lo extraordinario fue, alguna vez, revestido de un halo religioso. Mircea Eliade insiste en que el hombre encuentra manifestaciones de lo sagrado en todo lo que ama, necesita y siente. (...) El ímpetu religioso puede deberse a infinidad de factores: asombro, miedo, indefensión, deseos insatisfechos, traumas no superados, fijaciones infantiles, tendencias sexuales frustradas, ansias de superación, miedo a la muerte, prevención frente a lo desconocido" (Fraijó 1994: 31-39).

En particular, como ha subrayado Gómez Caffarena, en lo referido al sacrificio, quedaría sin justificar por qué Girard habría de ser tan riguroso a la hora de ver el origen mismo de lo sagrado en la etimología del sacrum-facio. Así, en línea con la reivindicación que acabamos de hacer de la diversidad del espectro de la experiencia religiosa, afirma: “Sagrado' parece ser más complejo y abarcante. Se han llamado también 'sacrificio' simples ofrendas que refuerzan la plegaria sin inmolación destructiva; y la misma inmolación podría haber simbolizado a veces reconocimiento del pleno dominio divino" (Gómez Caffarena 2007: 55-56) (5).

También, en referencia a una mayor diversidad de funciones de lo religioso que la destacada por Girard, A. Boyer considera que quizás no es incompatible con la teoría girardiana considerar "que lo religioso sirve a otros fines que la limitación de la rivalidad mimética: comprender el orden natural, asegurarse de un dominio 
parcial de éste -en particular de su fecundidad, etc." (Boyer 1985: 585)(6).

Por otra parte, echamos en falta también, en tanto que Girard considera una perspectiva diacrónica y evolutiva de la historia de la humanidad, una mínima mención al tiempo eje de K. Jaspers, de tal modo que habría podido utilizar esta noción para buscar concomitancias en ese tiempo eje, en lo que al cuestionamiento de los sacrificios religiosos se refiere, interpretando, por ejemplo, el proceso a Sócrates como otra perspectiva anti-mítica coincidente con la Pasión pero distinta de ella. En opinión de Boyer, Girard no puede

"asegurar que el cristianismo primitivo constituye históricamente la única alternativa a lo sagrado. ¿Puede asegurar también que los Evangelios son la única revelación y denuncia del mecanismo sacrificial? (7) Sócrates, por ejemplo, ¿no se proclama inocente él mismo y no acusa a la multitud de no haber respetado las leyes? Si rechaza huir, no es porque acepte su victimización, sino al contrario porque huir equivaldría a reconocer su culpabilidad. Sócrates no acepta ser chivo expiatorio" (Boyer 1985: 584)(8).

Una de las banderas enarboladas por Girard es la recuperación de la pregunta por los orígenes de la humanidad, cuestión relegada al olvido por las corrientes dominantes en los estudios etnológicos, centrados en las diferencias y particularidades de cada cultura. Las grandes pretensiones de la teoría mimética, queriendo dar cuenta de los albores de la especie humana y ofrecer una teoría de la cultura mediante el principio del mimetismo; su impugnación y sus críticas de sistemas filosóficos; su afán por haber ofrecido una explicación por vez primera inteligible y coherente del universo mitológico y una genuina interpretación del cristianismo... han abonado el terreno no sólo para la exaltación del autor, que ha recibido apelativos como el "Darwin de las ciencias sociales" o el "Hegel del cristianismo", sino también para la controversia, siendo también objeto de la acusación de megalómano galopante, a veces de forma satírica y exagerada:

"René Girard nació un 25 de diciembre. No podría tratarse de un puro azar. ¿Cómo no ver aquí, al contrario, un signo muy claro enviado por la divina Providencia, para hacernos comprender que René Girard estaba destinado a completar y perfeccionar el mensaje que Ella tenía, hace más de dos mil años, encargado a su Hijo único de aportar a los hombres? Convendría entonces, me parece, que de ahora en adelante, todos los cristianos festejasen, con tanto ardor, (...) el nacimiento de René Girard al mismo tiempo que el de Cristo. (...) que el papa convocase (...) un nuevo concilio ecuménico, que podría ser el último, para integrar en la Revelación cristiana la aportación indispensable de las teorías girardianas. (...) René Girard está persuadido de que él, y sólo él, gracias a la teoría mimética puede explicar todo aquello que es humano, tanto las conductas individuales como las conductas colectivas, la historia de los individuos, como las de los pueblos, las instituciones, las artes y las religiones" (Pommier 2010: 9-12).

Si bien hay algunas formulaciones en las teorías de Girard que pudieran dar pie a sustentar parte del fondo de estas críticas, no es menos cierto que muchas otras matizaciones rebajan el supuesto "mesianismo" girardiano o su soberbia, como apunta en este caso L. Scubla en el Colloque de Cerisy:

"Todos los que están aquí han podido apreciar su extrema modestia y saben que no deja nunca de recordar el carácter incompleto y parcial de su investigación y de sus resultados. 'Hay lugar para pensar, escribe él al final de El misterio de nuestro mundo, que aspectos muy importantes nos escapan que serán un día desvelados'. Es muy probable; ¿y no conviene, desde este momento, inscribir el mecanismo victimario en el número de hipótesis revisables de la ciencia más bien que en el de las verdades reveladas de la teología?" (Scubla 1985: 255).

O, como afirma el propio Girard, a quien también creemos en sintonía con Scubla: "Para tranquilizar a quienes temen cierto toque de megalomanía en mi conducta, debo agregar que no considero que esa intuición mía sea realmente personal. Creo que está "en el aire" y que si yo no hubiera dado con ella algún otro la habría tenido rápidamente" (Girard 1997: 209).

\section{La crítica al carácter no falsable de la teoría mimética y su mutilación de la diversidad}

Otro par de críticas que cabría hacer a la hipótesis del mecanismo victimario de Girard serían, por un lado la 
de su carácter no falsable y, por otro, en línea con lo apuntado anteriormente acerca del reduccionismo, el que una teoría de tan vasto alcance lo sea a costa de la diversidad tan rica y compleja del universo de lo religioso. Girard se defiende a este respecto esgrimiendo que su tesis, precisamente, se fundamenta en una vasta y numerosa diversidad de ejemplos y acusa a sus detractores de no comprenderle bien. Merece la pena leer su autodefensa:

"Se basa enteramente en inferencias estructurales y se impone gracias al número y variedad de ejemplos que pueden aducirse en su apoyo. (...) Todos los sistemas religiosos tomados en su conjunto constituyen una combinación de constantes y variables que el espíritu científico moderno se siente irresistiblemente tentado a convertir en alguna clase de enigma o acertijo, en otras palabras, algo que sería posible desentrañar. Tarde o temprano el péndulo se correrá a la otra posición una vez más y tornará a despertarse el interés en la religión per se. Aquellos que me acusan de descuidar los detalles concretos y las precisas estructuras del material antropológico que utilizo son ellos mismos culpables de la misma negligencia. Echan una breve mirada a mi hipótesis y dicen 'No me parece correcta' o ' $\mathrm{Si}$ fuera verdadera, nosotros ya lo sabríamos'. La mayor parte de mis críticos sencillamente no comprende aquello a lo que quiero referirme. Por ejemplo, cuando declaran que es imposible 'reducir' instituciones tan diversas como las instituciones religiosas a un solo 'concepto', no advierten que, para mí, la religión es 'siempre ya' interpretativa y que sus interpretaciones no pueden dejar de ser diferentes porque, por definición, deben apartarse de la verdad del mecanismo de la víctima propiciatoria" (Girard 1997: 210212).

Girard también se ha manifestado acerca de la cuestión de la falsabilidad y del carácter científico de la teoría mimética. Recordamos que la crítica que desde el falsacionismo popperiano se ha aplicado a sistemas de pensamiento como el marxismo o el psicoanálisis, o a las predicciones de horóscopos y adivinos, incidía en su carácter cerrado, imposible de refutar, ya que había una explicación para todo, o el tipo de afirmaciones que se vertían eran lo suficientemente vagas, generales, laxas o imprecisas como para tampoco poder ser impugnadas. Para Popper la racionalidad equivale a apertura a la crítica, siendo una alternativa a la violencia. Sus requisitos para que una hipótesis sea digna de ser calificada como científica serían: no ser refutada y ser refutable, aún consciente de que la ciencia es "hija del mito", aunque hija emancipada (Boyer 1985: 571). ¿Es la teoría mimética falsable? ¿Es imprescindible el requisito de la falsabilidad para determinar el carácter científico de una teoría, o aún para determinar su consistencia? Los críticos del falsacionismo han objetado, con acierto, que, de ser así, teorías como la de Einstein, en el momento de su formulación habrían quedado fuera de la ciencia, en tanto que aún no se podía llevar a cabo su posible falsación. No obstante, no nos detenemos en el debate.

Al respecto de la cuestión de la falsabilidad y la teoría mimética es interesante el trabajo de A. Boyer, ya citado, que lleva por título "Sacrifice et rétutation", en el que confronta la teoría girardiana con la filosofía de Popper, asumiendo que la cuestión de la cientificidad de la hipótesis mimética y victimaria, constantemente reivindicada por Girard es ineludible, más allá de su refutabilidad o su no refutabilidad. Boyer no se atreve a determinar si la teoría girardiana, tal como estaba formulada en el momento en que escribe, era falsable o estaba protegida contra la falsación. No obstante, observa que una de las críticas más a menudo expresadas por Girard en sus disputas con otras teorías del deseo (Freud, Lacan, Deleuze-Guattari) incide, precisamente, en cuestionar la manera en que sus partidarios intentan desarmar a sus adversarios sin entrar al "combate", recurriendo a "explicar" las razones por las cuales sus oponentes podrían cuestionarles o rechazar sus postulados, utilizando esto como un argumento a su favor (Boyer 1985: 576). El propio Girard ha cuestionado la clausura epistemológica del psicoanálisis: "Al igual que todo pensamiento mítico, el psicoanálisis es un sistema cerrado y nada puede nunca refutarlo" (Girard 1983: 96). Una crítica que, por cierto, también sería susceptible de ser recibida por algunas de las reduccionistas formulaciones de la teoría de Girard.

Aunque Boyer distingue tres conjuntos de hipótesis en el seno de la teoría mimética (teoría del deseo mimético; teoría de la víctima emisaria y teoría del judeocristianismo), nos limitamos a subrayar su valoración positiva de elementos de la teoría en general: su audacia y su generalidad, la pretensión de universalidad de sus explicaciones, en un marco en el que la cuestión de la aspiración a la Verdad es más importante que el de la cientificidad y donde esta no es un fin en sí mismo, sino más bien un filtro susceptible de permitirnos ser bastantes severos con nuestras producciones intelectuales, para que cualquier cosa no pueda pretender ser verdadera a toda costa (Boyer 1985: 575, 577, 572). Destacamos además la coincidencia señalada por el autor entre Girard y Popper. Ambos criticarían bajo la denominación de 
"platonismo", la tendencia freudiana a añadir hipótesis, por ejemplo apoyándose en "pulsiones", en cada ocasión que los "hechos", testarudos, resisten. Boyer también considera que la formulación de una buena teoría como improbable (audaz), refutable, y corroborada (no refutada a pesar de nuestras tentativas sinceras en este sentido), corresponde aproximadamente a lo que Girard presenta como la situación de su teoría, con la excepción crucial de la insistencia sobre la refutablidad "efectiva", cosa que este autor critica, resultándole inútil el recurso a lo que considera el “ídolo de la 'certidumbre'” (Boyer 1985: 575, 577, 572)(9).

Girard se remite a la supuesta actitud aparejada a este recurso y se defiende con un ejemplo referido a su interpretación de los textos históricos de persecución:

"Se irritan ante mi supuesta arrogancia. Creen posible darme lecciones de modestia sin el menor riesgo. (...) Se me opone asimismo la 'falsificación' de Popper y otras lindezas que nos llegan de Oxford, de Viena y de Harvard. Para estar en lo cierto, hay que cumplir unas condiciones tan draconianas que ni las ciencias más duras pueden tal vez satisfacer. (...) Nuestra demistificación de Guillaume de Machaut no es 'falsificable' (sic) en el sentido de Popper. ¿Es preciso, pues, renunciar a ella? [...] Debemos condenar retrospectivamente a los que terminaron con los procesos de brujería. Eran aún más dogmáticos que los cazadores de brujas y, al igual que éstos, creían poseer la verdad. ¿Hay que desestimar sus pretensiones? (Girard 1986: 133).

Dándole la vuelta a la tortilla y luciendo músculo de pensador crítico, Girard acusa la degeneración de la sofisticación del pensamiento crítico que, de haber caracterizado a las generaciones precedentes no habrían sido capaces de poner fin a la caza de brujas, por su incapacidad de afirmar que estaban en lo cierto cuando impugnaban esta, en el ejercicio mismo del pensamiento crítico y de la desmitificación:

"El pensamiento crítico se halla en un estado de extrema decadencia, esperemos que temporal, pero no por ello la enfermedad es menos aguda pues se cree el supremo refinamiento del espíritu crítico. Si nuestros antepasados hubieran pensado de la misma manera que creen los que ahora mandan, jamás habrían terminado con los procesos de brujería" (Girard 1986: 134).

En un tono más que a la defensiva, a la ofensiva, el creador de la teoría mimética cuestiona directamente el falsacionismo popperiano:

"La tesis de Karl Popper según la cual toda teoría científica debe ser falsable no se tiene en pie. El hecho de que la tierra gire alrededor del sol, más bien que lo contrario, no será nunca puesto en cuestión. Lo mismo en lo que se refiere a la circulación de la sangre. Se trata, más que de hipótesis científicas, casi del fruto de determinadas experiencias. Hoy, cuando usted ve elevarse el sol, no se le ocurre imaginarse que surge de la tierra. Sabe perfectamente que la tierra gira. (...) Se trata de lo mismo por lo que respecta a la caza de brujas de la Edad Media. ¿Qué ocurriría si, a propósito de una caza de brujas, alguien le dijera: 'Ah, es una intervención divina'? Se reiría usted de él, porque sabe de manera pertinente que es falso. No tiene usted necesidad de hipótesis científica porque los indicios son demasiado numerosos" (Girard 2006: 116).

En el plano de la psicología experimental el pensador también evoca el interés que tendría la experimentación desde esta disciplina en relación con la teoría mimética, aunque, al mismo tiempo que reprocha que en este ámbito no se conozca su teoría, vuelve sobre la dificultad de la comprobación científica de la teoría mimética. Entre otras cosas por la afección mimética del propio investigador de los fenómenos miméticos. Girard también esgrime la complejidad del conjunto de su teoría, lo cual sobrepasaría, en su opinión, el alcance de la comprobación científica y la falsación popperiana. Dice disponer de mucho material de psicólogos experimentales sobre imitación, lo que verificaría que la imitación precede a la conciencia y al lenguaje, pero afirma que:

"Desafortunadamente, los psicólogos experimentales no son conscientes aún de su existencia, parece. Además, no es fácil probar. Necesitas parámetros y controles durante largos periodos de tiempo y un modo de analizar el orden social de los sujetos, del cual el experimentador es también una parte. El experimentador también está envuelto en mímesis. Por tanto es muy difícil probar de un modo que realmente reúna requerimientos científicos. Es siempre bonito verificar lo obvio científicamente. Probablemente sería una buena cosa si algunos investigadores tomando la teoría mimética hicieran ese tipo de comprobación. Sería una clase de validación, pero lo sería de valor limitado. No sería en el nivel intelectual de la teoría como un todo, la mayor parte del cual no puede estar sujeto a la verificación 
empírica o la falsación a través de comprobación empírica o los cánones de la ciencia contemporánea, especialmente el principio de falsabilidad. La complejidad de aquello sobre lo que estamos hablando es demasiado grande para ello" (Williams 1996: 277).

No obstante lo cual, a comienzos de la misma década de los noventa, de la que data la entrevista a la que pertenece este fragmento, se produce en la Universidad de Parma el hallazgo de las neuronas espejo, saludado por Girard, que subrayaría la importancia de la imitación e indicaría el componente neurológico de esta, con un papel capital en las capacidades cognitivas relacionadas con la vida social, la empatía, las habilidades mentales o el lenguaje.

\section{Conclusión}

Llegados a este punto, creemos haber expuesto las principales líneas de aspectos controvertidos y susceptibles de crítica en la teoría mimética de Girard, aunque no los hayamos agotado todos, tampoco en sus implicaciones, ni desarrollado extensamente. Los hemos abordado en un plano más formal, referido: a su interpretación de textos y autores filosóficos (poniendo a Platón como ejemplo); a su concepción de los mitos (aludiendo a una posible selección parcial); y a su teoría acerca del judeocristianismo (exponiendo el cuestionamiento de su lectura de los textos judeocristianos). También hemos apuntado a una serie de críticas más centradas en los contenidos ligados a los dos aspectos clave de bóveda de la teoría mimética: el deseo mimético y el mecanismo del chivo expiatorio.

En lo que se refiere al deseo mimético, hemos enfatizado la crítica a su posible planteamiento reduccionista y a la ausencia en Girard de un reconocimiento del mimetismo violento, más allá de la presencia de dos rivales, tanto en un plano ontogénico como filogenético. Con respecto al mecanismo del chivo expiatorio, hemos vuelto sobre la crítica al reduccionismo, esta vez en relación a la mutilación girardiana de la complejidad de la esfera religiosa. Además, hemos abierto el espectro de la genuina crítica a la religión sacrificial, más allá del neto protagonismo del cristianismo (aunque Girard no lo exclusiviza), y abordado la crítica a la megalomanía de Girard. Tras este elenco de críticas que, ni mucho menos significan o implican una impugnación de la teoría mimética, volviendo a un plano más general, y a modo de conclusión abierta, consideramos que Girard podría asumir las siguientes palabras de Boyer, que finalizan con un cumplido:

"Digo simplemente que todas las situaciones no son, en todo caso en el mismo grado, de tipo "girardiano". Hay quizás de lo mimético por todo, pero no hay sólo más que mimetismo. Y no creemos salvar la tesis radical diciendo que el "deseo mimético" está "reprimido". R. Girard se guarda bien de recurrir a esta estrategia inmunizante demasiado conocida para impresionar todavía" (Boyer 1985: 582).

\section{Notas}

1. Para aquellos lectores no familiarizados con la teoría girardiana remitimos a los resúmenes que se hallan en los siguientes trabajos anteriores: Moreno Fernández 2011: 59-63; Moreno Fernández 2010: 1 y ss.

2. Se trata de los Dioscuros, "hijos de Zeus", gemelos. "Crecieron en Esparta, cuando ya su padre, ayudado por Heracles, había recuperado el trono de la ciudad. Eran de gran belleza, y destacaban entre los demás jóvenes, Cástor en el manejo de las armas y la doma de los caballos, y Pólux en el pugilato. Lejos de rivalizar entre sí, como otros mellizos, los Dioscuros se amaban entrañablemente, y aparecen siempre juntos en las distintas hazañas que les atribuye la tradición" (Falcón 2001: 178-179).

3. Sin entrar a valorarlos, observamos que Pommier realiza interpretaciones sesgadas y descontextualizadas de pasajes de la obra de Girard, si bien en ocasiones, como al hilo del ambivalente "deseo espontáneo" de Mentira romántica y verdad novelesca, el punto de partida es una deficiencia del autor de la teoría mimética. No obstante, autores como Maurel afirman al respecto de los temas miméticos en las obras literarias lo siguiente: "Fenómenos de dobles, los ritos, la monarquía, los monstruos. (...) el 
lector pensará quizás que sólo encontramos estos fenómenos en las obras porque los buscamos allí y a fuerza de interpretaciones abusivas. Para responder a esta objeción, sólo podemos reenviar al lector a los estudios de René Girard sobre Cervantes, Dostoïevski o Proust y, si se siente dispuesto a abordarlos, a los estudios contenidos en este volumen. Podrá juzgar por sí mismo si estas interpretaciones son abusivas, o si, al contrario, aportan sobre obras bien conocidas una nueva iluminación" (Maurel 2004: 11). Entre otras obras analizadas por Maurel: Romeo y Julieta o Cándido. Sobre estas y las demás obras, al igual que las analizadas por Girard, concluye el hecho de que "estas revelan una verdad profunda y esencial: la realidad del deseo mimético en la cual vivimos. (...) Si todas ellas se desenvuelven sobre un fondo de conflicto colectivo más o menos vasto, es que el conflicto mimético permanente es la realidad de la vida" (Maurel 2004: 195).

4. Para ser ecuánimes hay que decir que Girard sí reconoce la especial fragilidad y falta de protección de los niños ante el "violento" double-bind en que se ven envueltos por los adultos. Es decir, el doble imperativo contradictorio, en que consiste obedecer al imperativo subyacente que veríamos en los deseos representados por nuestros modelos ("imítame") que, al mismo tiempo que se muestran como deseables y susceptibles de ser imitados, ordenarían el imperativo contrario ("no me imites"), significado en la imposibilidad de alcanzar los objetos poseídos por el modelo y su deseo de que no sea así.

5. Reflejamos aquí parte de una serie de apostillas críticas que también incluyen valoraciones positivas: "No es fácil comprender con precisión el sacrificio a partir de los datos histórico-etnológicos. Pero es aleccionadora la tendencia a su espiritualización en religiones posteriores (cristianismo); o, incluso, hacia su total supresión (budismo, Islam). Por ello, es mejor remitir su estudio a un contexto más amplio de evolución religiosa. Por lo demás, es importante haber constatado, con ocasión de los ritos sacrificiales, la alarmante implicación entre religión y violencia: ha habido una específica y no pequeña violencia religiosa. La violencia es, en cualquier caso, una parte muy importante del mal que sufre la humanidad; algo para lo que podría esperar 'salvación' de las religiones. ¿Por qué no podría -y ésta sería posiblemente la más apreciable aportación de Girard- la implicación entre religión y violencia cambiar de signo?” (Gómez Caffarena 2007: 56).

6. Continúa la cita con este interesante apunte que es la conclusión de su confrontación entre Girard y Popper a la que nos referiremos a continuación: "Retomando una idea de Popper y de su amigo el historiador del arte Gombrich, podríamos suponer que todo instrumento que sirve a una gran multiplicidad de fines será más difícil de cambiar que un objeto monofuncional. La multifuncionalidad de lo religioso acentuaría su resistencia al cambio. La 'sociedad orgánica', en el sentido de Durkheim, favorecería al contrario la especialización y la evolución de las instituciones: nuestra cultura, y sus nuevos problemas, habría nacido de la dispersión del sacrificio" (Boyer 1985: 585).

7. Girard no identifica el cristianismo como el único cuestionamiento de la religión sacrificial arcaica, si bien sería el más genuino y completo. Para hacerse cargo de las diversas tradiciones religiosas en las que se hallaría según el pensador una crítica de los sacrificios véase Moreno Fernández 2011: 57-86.

8. "Cf. Apología, 37 a: 'Estoy convencido, yo, de que no he hecho mal a nadie voluntariamente, pero rechazáis creerme', y Criton, 54 c:, en la boca de las leyes: 'Si tu partes hoy hacia el otro mundo, tu partirás condenado injustamente no por nosotras, las leyes, sino por los hombres'. No estoy en consecuencia de acuerdo por lo que Girard dice de Sócrates, en l'Auto-organisation, p. 291" (Boyer 1985: 589, nota n 82). Recordamos lo que decía allí el pensador: "Es cierto que hay en los griegos cosas extraordinarias. Es Simone Weil, bajo mi punto de vista, quien ha hablado mejor de ello, en un libro cuya traducción inglesa se titula Intimations of Christianity, pero reconoce que esta es una lectura voluntariamente anacrónica. Si vemos en Antígona una heroína de la lucha contra la persecución, es de una cierta manera a través de los profetas y el cristianismo. (...) Pero Sócrates, al final, vuelve hacia la ciudad, acepta su muerte y las leyes de la ciudad. Jeremías, varios siglos antes, dice: si continuáis actuando como hacéis, Dios abandonará el templo y se ha terminado. Hay aquí una diferencia. No hay jamás en los griegos denuncia parecida de la sociedad en tanto que tal" (Dumouchel 1983: 291).- Castoriadis, como Boyer, tras la cita que hemos transcrito, continúa su argumentación esgrimiendo que es todo lo contrario a lo que afirma Girard, apelando al nacimiento de la filosofía y la democracia en Grecia, aparejado al cuestionamiento sobre la sociedad y la religión, a la reflexión sobre la responsabilidad de la sociedad como comunidad política. Castoriadis, en particular, remite a Jenófanes, a su crítica al panteón griego, cuestionando la naturaleza de unos dioses sospechosos por su carácter antropomórfico; a Homero y su referencia a las víctimas causadas y vencidas 
por los griegos.

9. En una nota al final, se nos remite al siguiente fragmento de El chivo expiatorio: "Para merecer este título glorioso [de científico] hay que combinar el máximo de incertidumbre actual y el máximo de certidumbre potencial. Eso es precisamente lo que combina mi hipótesis" (Boyer 1985: 587, nota n 53; Girard 1986: 132).

\section{Bibliografía}

Andrade, Gabriel

2007 La crítica literaria de René Girard, Mérida, Venezuela, Ed. del Vice Rectorado Académico Universidad del Zulia.

Boyer, A.

1985 "Sacrifice et réfutation", en P. Dumouchel (dir.), Violence et vérité autour de René Girard, París, Grasset : 569-589.

Dumouchel, Paul (y Jean Pierre Dupuy) (dir.)

1983 L'auto-organisation. De la physique au politique, París, Éditions du Seuil.

Dumouchel, Paul (dir.)

1985 Violence et vérité autour de René Girard, París, Grasset.

Falcón, Carlos (y otros)

2001 Diccionario de mitología clásica, 1, Madrid, Alianza Editorial.

Fraijó, Manuel

1994 Filosofía de la religión. Estudios y textos, Madrid, Trotta.

Girard, René

1983 La violencia y lo sagrado, Barcelona, Anagrama.

1986 El chivo expiatorio, Barcelona, Anagrama.

1997 Literatura, mímesis y antropología, Barcelona, Gedisa.

2006 Aquel por el que Ilega el escándalo, Madrid, Caparrós.

Gomá Lanzón, Javier

2005 Imitación y experiencia, Barcelona, Crítica.

Gómez Caffarena, José

2007 El Enigma y el Misterio. Una filosofía de la religión, Madrid, Trotta.

González Faus, José lgnacio

1998 “ ¿De la historia a Dios? ¿O de la violencia sagrada al Dios de la víctima? Presentación de René Girard", en Fe en Dios y construcción de la historia, Madrid, Trotta.

Maurel, Olivier

2004 Essais sur le mimétisme. Sept oeuvres littéraires et un film revisités à la lumière de la théorie de René Girard. París, L'Harmattan.

Moreno Fernández, Agustín

2010 "René Girard y su crítica de la etnología multiculturalista y relativista", en Gazeta de Antropología, n²6: texto $26-28$.

http://digibug.ugr.es/handle/10481/6765

2011 "La violencia en las religiones según la teoría mimética de Girard", en C. Castilla (coord.), El diálogo interreligioso, Granada, Comares, 2011: 57-86.

2013 La evaluación de la modernidad en la teoría mimética de René Girard. Deseo, violencia, religión y 
libertad, Granada, Ed. Universidad de Granada, 2013.

http://hdl.handle.net/10481/26378

Pommier, René

2010 René Girard. Un allumé qui se prend pour un phare, París, Kimé.

Scubla, Lucien

1985 “Le christianisme de René Girard et la nature de la religion”, en P. Dumouchel (dir.), Violence et vérité autour de René Girard, París, Grasset.

Vinolo, Stéphane

2005 René Girard: Du mimétisme à I'hominisation, París, L'Harmattan.

Williams, J. G.

1996 "The Anthropology of the Cross: A Conversation with René Girard", en R. Girard: The Girard Reader, ed. by J. G. Williams, New York, Crossroad Herder: 262-288. 